Case Report

\title{
Triple Diuretics and Aquaretic Strategy for Acute Decompensated Heart Failure due to Volume Overload
}

\author{
Rita Jermyn, ${ }^{1}$ Naveed Rajper, ${ }^{2}$ Chelsea Estrada, ${ }^{3}$ Sagar Patel, ${ }^{3}$ Michelle Weisfelner Bloom, ${ }^{1}$ \\ and Nand K. Wadhwa ${ }^{3}$ \\ ${ }^{1}$ Division of Cardiology, Department of Medicine, Stony Brook Medicine, Stony Brook, NY 11794, USA \\ ${ }^{2}$ Department of Medicine, Stony Brook Medicine, Stony Brook, NY 11794, USA \\ ${ }^{3}$ Division of Nephrology, Department of Medicine, Stony Brook Medicine, Stony Brook, NY 11794, USA
}

Correspondence should be addressed to Nand K. Wadhwa; nand.wadhwa@stonybrookmedicine.edu

Received 4 November 2013; Accepted 27 November 2013

Academic Editors: H. Kataoka, A. Movahed, and Y. Naito

Copyright (C) 2013 Rita Jermyn et al. This is an open access article distributed under the Creative Commons Attribution License, which permits unrestricted use, distribution, and reproduction in any medium, provided the original work is properly cited.

\begin{abstract}
Diuretics, including furosemide, metolazone, and spironolactone, have historically been the mainstay of therapy for acute decompensated heart failure patients. The addition of an aquaretic-like vasopressin antagonist may enhance diuresis further. However, clinical experience with this quadruple combination is lacking in the acute setting. We present two hospitalized patients with acute decompensated heart failure due to massive fluid overload treated with a combination strategy of triple diuretics in conjunction with the aquaretic tolvaptan. The first patient lost $72.1 \mathrm{lbs}$. $(32.7 \mathrm{~kg}$ ) with an average urine output of 3.5 to $7.5 \mathrm{~L} / \mathrm{day}$ over eight days on combined therapy with furosemide, metolazone, spironolactone, and tolvaptan. The second patient similarly achieved a weight loss of $28.2 \mathrm{lbs}$. (12.8 kg) over 4 days on the same treatment. Both patients maintained stable serum sodium, potassium, and creatinine over this period and remained out of the hospital for more than 30 days. Thus, patients hospitalized with acute decompensated heart failure due to volume overload can achieve euvolemia rapidly and without electrolytes disturbances using this regimen, while being under the close supervision of a team of cardiologists and nephrologists. Additionally, this therapy can potentially decrease the need for ultrafiltration and the length of hospital stay.
\end{abstract}

\section{Introduction}

Patients with congestive heart failure decompensate mainly because of enhanced sympathetic, arginine vasopressin, and renin-angiotensin-aldosterone activation [1]. This neurohumoral activation leads to upregulation of the reninangiotensin system and intrarenal vasoconstriction which accelerates renal sodium and water retention leading to volume overload [2]. Diuretics have historically been the mainstay of therapy during heart failure admissions $[3,4]$. Tolvaptan has been utilized to improve fluid and osmotic balance by inhibiting water retention without altering electrolytes in acute decompensated heart failure (ADHF) [5-7]. However, if the patient concurrently has a marked reduction in their glomerular filtration rate, diuretic resistance becomes more probable. In oliguric and anuric ADHF patients with severe volume overload and need for aggressive diuresis, ultrafiltration is a successful treatment strategy for achieving optimal volume control [8]. The safe use of tolvaptan in combination with diuretics has been reported in patients with decompensated heart failure due to volume overload [9-11]. We developed a combination protocol of furosemide, metolazone, spironolactone, and tolvaptan to augment volume loss by increasing urine output while maintaining electrolyte stability in the intravascular space before considering ultrafiltration. Here, we report our experience in two hospitalized cardiorenal patients with ADHF due to massive volume overload treated with a triple diuretics and aquaretic therapy consisting of furosemide, metolazone, spironolactone, and tolvaptan under close monitoring of serum electrolytes.

\section{Case 1}

A 67-year-old white man presented to the emergency room with progressive dyspnea and along with a weight gain of $20 \mathrm{lbs}$. $(9.1 \mathrm{~kg})$ within three weeks. Cardiac history was 
significant for a dilated ischemic cardiomyopathy (New York Heart Association class III), status after revascularization with coronary artery bypass grafting (CABG) and stents, left ventricular ejection fraction (LVEF) of 35\%, severe diastolic dysfunction, and chronic kidney disease (CKD) stage 4 due to cardiorenal syndrome. On physical examination, the patient was afebrile and in mild respiratory distress, with difficulty speaking full sentences. His blood pressure was $104 / 71 \mathrm{mmHg}$, heart rate was $55 / \mathrm{min}$, respiratory rate was $18 / \mathrm{min}$, and oxygen saturation was $92 \%$ on $4 \mathrm{~L}$ nasal cannula. His weight was 159.2 kilograms. He had jugular venous distension to the angle of the mandible. Cardiac exam revealed regular rhythm with an $\mathrm{S} 3$ gallop. Lung exam showed bilateral rales. Abdomen was protuberant with ascites. Laboratory data revealed serum sodium of $137 \mathrm{mmol} / \mathrm{L}(\mathrm{mEq} / \mathrm{L})$, potassium of $5.2 \mathrm{mmol} / \mathrm{L}(\mathrm{mEq} / \mathrm{L})$, creatinine of $2.5 \mathrm{mg} / \mathrm{dL}$ $(221 \mu \mathrm{mol} / \mathrm{L})$, chloride of $101 \mathrm{mmol} / \mathrm{L}(\mathrm{mEq} / \mathrm{L})$, and bicarbonate of $30 \mathrm{mmol} / \mathrm{L}(\mathrm{mEq} / \mathrm{L})$. His B-type natriuretic peptide was $456 \mathrm{pg} / \mathrm{mL}(\mathrm{ng} / \mathrm{L})$. Chest roentgenogram showed large right and moderate left pleural effusions. He was treated with a triple diuretics and aquaretic regimen (Table 1) to optimize his severe volume overload. Over the course of eight days with this combination therapy, the patient achieved a $72.1 \mathrm{lbs}$. (32.7 kg) weight loss. His serum creatinine improved to $2.12 \mathrm{mg} / \mathrm{dL}(187.4 \mu \mathrm{mol} / \mathrm{L})$, while his serum electrolytes remained stable as shown in Figure 1(a). This regimen expedited weight loss with resolution of dyspnea. The patient successfully remained out of the hospital for over thirty days.

\section{Case 2}

A 79-year-old white man presented to the emergency room with a weight gain of $15 \mathrm{lbs}$. $(6.8 \mathrm{~kg})$ over two weeks associated with progressive bilateral pitting edema and paroxysmal nocturnal dyspnea. His medical history included a non-dilated ischemic cardiomyopathy with LVEF of 30\% (New York Heart Association class III), status-post CABG, status-post biventricular automatic implantable cardioverter defibrillator (AICD), and CKD stage 4 due to cardiorenal syndrome. Physical examination revealed temperature of $37.1 \mathrm{C}$, blood pressure of $103 / 55 \mathrm{mmHg}$, heart rate of $68 / \mathrm{min}$, respiratory rate of $17 / \mathrm{min}$, and oxygen saturation of $96 \%$ in room air. His weight was 88.8 kilograms. He had jugular venous distention. Cardiac exam revealed regular S1/S2 with a II/VI SEM radiating to left lateral axilla. His lung exam revealed bibasilar rales. His abdomen was markedly distended with ascites. The lower extremities had gross pitting edema up to the waist. His serum sodium was $130 \mathrm{mmol} / \mathrm{L}(\mathrm{mEq} / \mathrm{L})$, potassium was $5.1 \mathrm{mmol} / \mathrm{L}(\mathrm{mEq} / \mathrm{L})$, bicarbonate was $29 \mathrm{mmol} / \mathrm{L}(\mathrm{mEq} / \mathrm{L})$, and creatinine was $2.5 \mathrm{mg} / \mathrm{dL}(221 \mu \mathrm{mol} / \mathrm{L})$, with chloride of $100 \mathrm{mmol} / \mathrm{L}(\mathrm{mEq} / \mathrm{L})$ and B-type natriuretic peptide of $442 \mathrm{pg} / \mathrm{mL}$ (ng/L). Electrocardiogram showed no signs of acute ischemia. Chest roentgenogram showed pulmonary vascular congestion. He was managed with the triple diuretics and aquaretic regimen (Table 1) for ADHF. Over four days, the patient achieved a $28.2 \mathrm{lb}$. $(12.8 \mathrm{~kg})$ weight loss. His serum creatinine improved to $2.18 \mathrm{mg} / \mathrm{dL}(192.7 \mu \mathrm{mol} / \mathrm{L})$ with stable serum electrolytes as shown in Figure 1(b). He remained out of the hospital for over thirty days.
TABLE 1: Diuretics' protocol: doses of furosemide and metolazone were titrated based on urine output; spironolactone dose was titrated to maintain a serum potassium of $4-4.5 \mathrm{mmol} / \mathrm{L}(\mathrm{mEq} / \mathrm{L})$; tolvaptan dose was titrated to maintain a serum sodium of $131-139 \mathrm{mmol} / \mathrm{L}$ $(\mathrm{mEq} / \mathrm{L})($ based on the initial value, maximum correction was 6$8 \mathrm{mmol} / \mathrm{L}(\mathrm{mEq} / \mathrm{L})$ and not to exceed $139 \mathrm{mmol} / \mathrm{L}(\mathrm{mEq} / \mathrm{L})$ in 24 hours).

\begin{tabular}{|c|c|c|c|}
\hline $\begin{array}{l}\text { Diuretics and } \\
\text { suggested doses }\end{array}$ & $\begin{array}{l}\text { Laboratory } \\
\text { monitoring }\end{array}$ & $\begin{array}{l}\text { Serum } \\
\text { electrolyte goals }\end{array}$ & $\begin{array}{l}\text { Target fluid } \\
\text { loss }\end{array}$ \\
\hline $\begin{array}{l}\text { Furosemide: } \\
\text { infusion } \\
10-40 \mathrm{mg} / \mathrm{hr}\end{array}$ & $\begin{array}{l}\text { Serum } \\
\text { chemistry every } \\
6 \text { hours }\end{array}$ & $\begin{array}{l}\text { Sodium: } \\
131-139 \mathrm{mmol} / \mathrm{L} \\
(\mathrm{mEq} / \mathrm{L})\end{array}$ & 4-5 liters/day \\
\hline $\begin{array}{l}\text { Spironolactone: } \\
25 \mathrm{mg} \text { daily to } \\
50 \mathrm{mg} \text { three } \\
\text { times daily }\end{array}$ & $\begin{array}{l}\text { Urine } \\
\text { electrolytes } \\
\text { every } 6 \text { hours }\end{array}$ & $\begin{array}{l}\text { Potassium: } \\
4-4.5 \mathrm{mmol} / \mathrm{L} \\
(\mathrm{mEq} / \mathrm{L})\end{array}$ & \\
\hline \multicolumn{4}{|l|}{$\begin{array}{l}\text { Metolazone: } \\
5 \mathrm{mg} \text { twice daily } \\
\text { to } 10 \mathrm{mg} \text { twice } \\
\text { daily }\end{array}$} \\
\hline $\begin{array}{l}\text { Tolvaptan: } 15 \mathrm{mg} \\
\text { daily to } 30 \mathrm{mg} \\
\text { daily }\end{array}$ & & & \\
\hline
\end{tabular}

\section{Discussion}

We report two patients with ADHF due to severe volume overload and cardiorenal syndrome, who achieved clinical euvolemic status with the diuretics and aquaretic regimen including furosemide, metolazone, spironolactone, and tolvaptan within one week's time. Their renal function and serum electrolytes remained stable, and both patients stayed out of the hospital for more than thirty days. With frequent readmissions and lengthy hospitalizations for acute decompensated heart failure, this strategy might expedite restoration to a clinically euvolemic state and decrease thirtyday hospital readmission rates.

Ross et al. evaluated trends in readmission after ADHF hospitalization and found that 30 -day readmission rates from 2004 to 2006 ranged from $23.7 \%$ to $23.9 \%$ [12]. This suggests that newer approaches to treatment are much needed. Diuretics remain the mainstay of therapy for patients with ADHF. In the Diuretic Strategies in Patients with Acute Decompensated Heart Failure (DOSE) trial, Felker et al. noted no significant difference in patients' assessment of symptoms when the diuretic furosemide was administered by either bolus or continuous infusion [4]. A combination pharmacologic therapy using spironolactone, furosemide, and metolazone has been well described to improve diuresis [13]. However, in patients unable to achieve effective diuresis, ultrafiltration is viewed as an alternative regimen [8]. In the ultrafiltration versus intravenous diuretics for patients hospitalized for acute decompensated heart failure (UNLOAD) trial, ultrafiltration produced a greater weight loss at 48 hours $(5.0 \mathrm{~kg})$ compared to usual care $(3.3 \mathrm{~kg})(P=0.001)$ [14]. However, a more recent trial suggested that in hospitalized patients with decompensated heart failure, the use of pharmacotherapy was superior to ultrafiltration for preserving renal function 

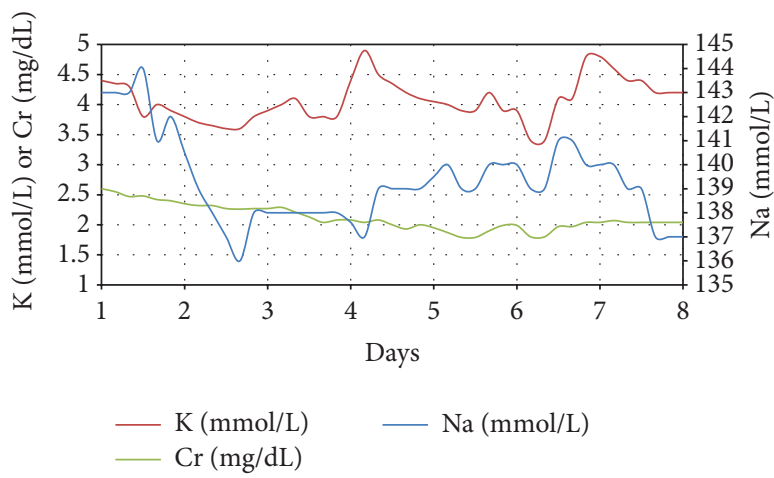

(a)

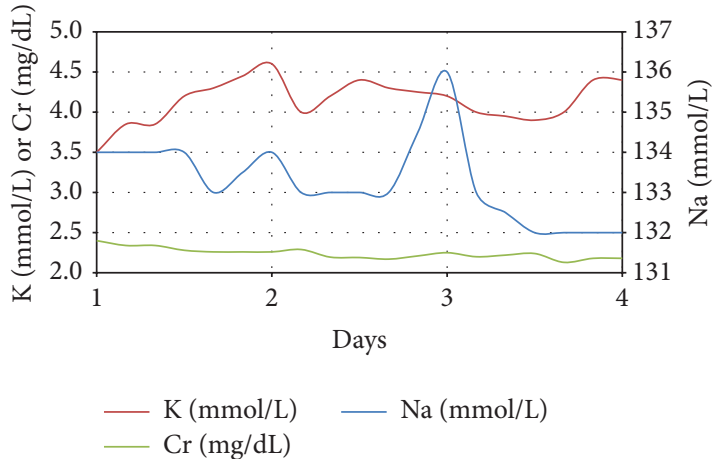

(b)

FIGURE 1: Change in serum potassium, sodium, and creatinine during treatment with quadruple therapy in Case 1 (a) and Case 2 (b).

and achieving weight loss with fewer adverse events [15]. A stepped-up pharmacologic care utilized loop and thiazide diuretics as well as inotropes and intravenous vasodilators [15]. Given the limitations of current available therapies, it seemed reasonable to look for additional strategies using medical therapy. Efficacy and safety of tolvaptan with the concurrent use of diuretics have been reported in patients with decompensated heart failure due to volume overload [7, 9-11]. Tolvaptan as an additional therapy in ADHF patients also prevents hyponatremia which is seen with loop diuretics [6]. Therefore, we constructed a protocol with a combination of diuretics and aquaretic therapy to achieve rapid diuresis safely in hospitalized patients with ADHF and cardiorenal syndrome. Given the mechanisms of action of these drugs, we utilized their unique pharmacokinetic and pharmacodynamics properties to achieve rapid and effective diuresis while closely monitoring serum electrolytes and renal function. In the literature, it is well described that the therapeutic effect of diuretics is similar in nonischemic and ischemic cardiomyopathy, but response to some other drugs such as antiarrhythmics is better in nonischemic heart failure [16].

In conclusion, we describe a successful strategy in treating grossly volume overloaded acute decompensated heart failure patients, achieving high urine output while maintaining stable serum electrolytes and creatinine, and reducing 30day hospital readmission rates. We recommend that this protocol should only be used in the cardiac intensive care unit setting with close monitoring of serum electrolytes under the supervision of an experienced team of cardiologists and nephrologists.

\section{Conflict of Intersts}

The authors declare that they have no conflict of interests.

\section{References}

[1] M. Sarraf, A. Masoumi, and R. W. Schrier, "Cardiorenal syndrome in acute decompensated heart failure," Clinical Journal of the American Society of Nephrology, vol. 4, no. 12, pp. 20132026, 2009.
[2] B. Krämer, F. Schweda, and G. Riegger, "Diuretic treatment and diuretic resistance in heart failure," American Journal of Medicine, vol. 106, no. 1, pp. 90-96, 1999.

[3] S. Paul, "Balancing diuretic therapy in heart failure: Loop diuretics, thiazides, and aldosterone antagonists," Congestive Heart Failure, vol. 8, no. 6, pp. 307-312, 2002.

[4] G. M. Felker, K. Lee, D. A. Bull et al., "Diuretic strategies in patients with acute decompensated heart failure," The New England Journal of Medicine, vol. 364, no. 9, pp. 797-805, 2011.

[5] H. Masatsugu, "Tolvaptan for heart failure patients with volume overload," Cardiovascular Drugs and Therapy, vol. 25, no. 1, supplement 1, pp. S1-S4, 2011.

[6] M. Hori, "Tolvaptan for the treatment of hyponatremia and congestive heart failure," Future Cardiology, vol. 9, no. 2, pp. 163-176, 2013.

[7] M. A. Konstam, M. Gheorghiade, J. C. Burnett Jr. et al., "Effects of oral tolvaptan in patients hospitalized for worsening heart failure: the EVEREST outcome trial," The Journal of the American Medical Association, vol. 297, no. 12, pp. 1319-1331, 2007.

[8] N. K. Wadhwa, "Emergency dialysis and ultrafiltration," in Cardiac Intensive Care, D. Brown and A. Jeremias, Eds., pp. 196-202, Elsevier Health Sciences, Philadelphia, Pa, USA, 2nd edition, 2010.

[9] M. Gheorghiade, W. A. Gattis, C. M. O’Connor et al., "Effects of tolvaptan, a vasopressin antagonist, in patients hospitalized with worsening heart failure: a randomized controlled trial," The Journal of the American Medical Association, vol. 291, no. 16, pp. 1963-1971, 2004.

[10] J. E. Udelson, M. Bilsker, P. J. Hauptman et al., "A multicenter, randomized, double-blind, placebo-controlled study of tolvaptan monotherapy compared to furosemide and the combination of tolvaptan and furosemide in patients with heart failure and systolic dysfunction," Journal of Cardiac Failure, vol. 17, no. 12, pp. 973-981, 2011.

[11] M. Matsuzaki, M. Hori, T. Izumi, and M. Fukunami, "Efficacy and safety of tolvaptan in heart failure patients with volume overload despite the standard treatment with conventional diuretics: a phase III, randomized, double-blind, placebo-controlled study (QUEST study)," Cardiovascular Drugs and Therapy, vol. 25, no. 1, supplement 1, pp. S33-S45, 2011.

[12] J. S. Ross, J. Chen, Z. Lin et al., "Recent national trends in readmission rates after heart failure hospitalization," Circulation, vol. 3, no. 1, pp. 97-103, 2010. 
[13] K. S. Channer, K. A. McLean, P. Lawson-Mathew, and M. Richardson, "Combination diuretic treatment in severe heart failure: a randomised controlled trial," British Heart Journal, vol. 71, no. 2, pp. 146-150, 1994.

[14] M. R. Costanzo, M. E. Guglin, M. T. Saltzberg et al., "Ultrafiltration versus intravenous diuretics for patients hospitalized for acute decompensated heart failure," Journal of the American College of Cardiology, vol. 49, no. 6, pp. 675-683, 2007.

[15] B. A. Bart, S. R. Goldsmith, K. L. Lee et al., "Ultrafiltration in decompensated heart failure with cardiorenal syndrome," The New England Journal of Medicine, vol. 367, no. 24, pp. 2296-2304, 2012.

[16] F. Follath, J. G. F. Cleland, W. Klein, and R. Murphy, "Etiology and response to drug treatment in heart failure," Journal of the American College of Cardiology, vol. 32, no. 5, pp. 1167-1172, 1998. 


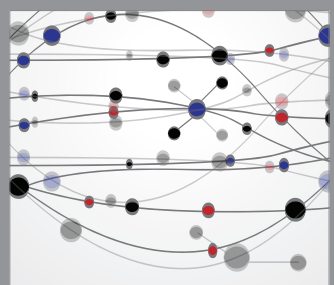

The Scientific World Journal
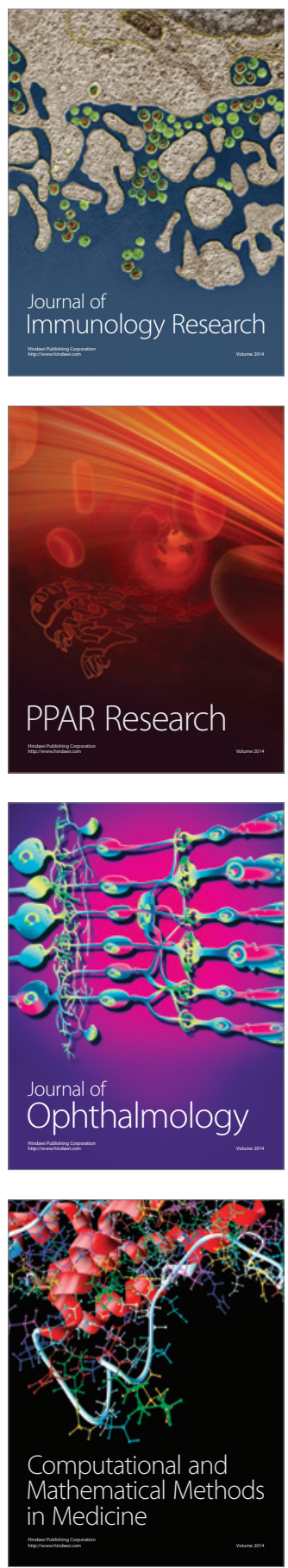

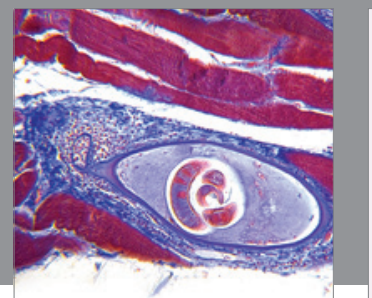

Gastroenterology

Research and Practice
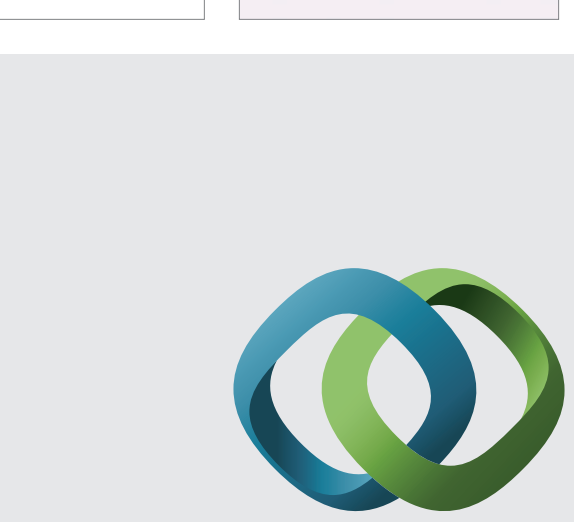

\section{Hindawi}

Submit your manuscripts at

http://www.hindawi.com
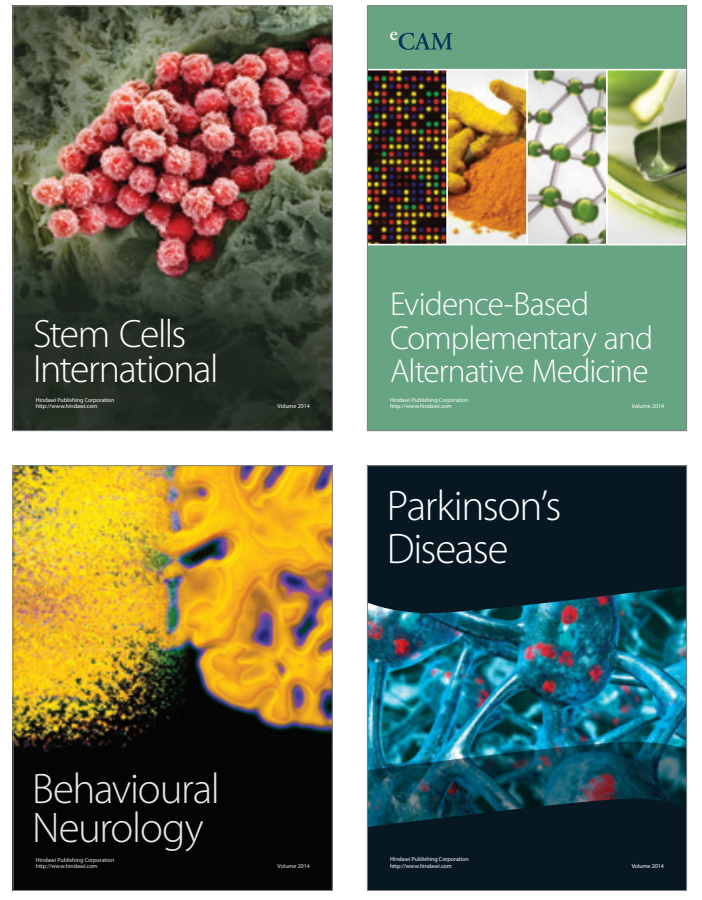
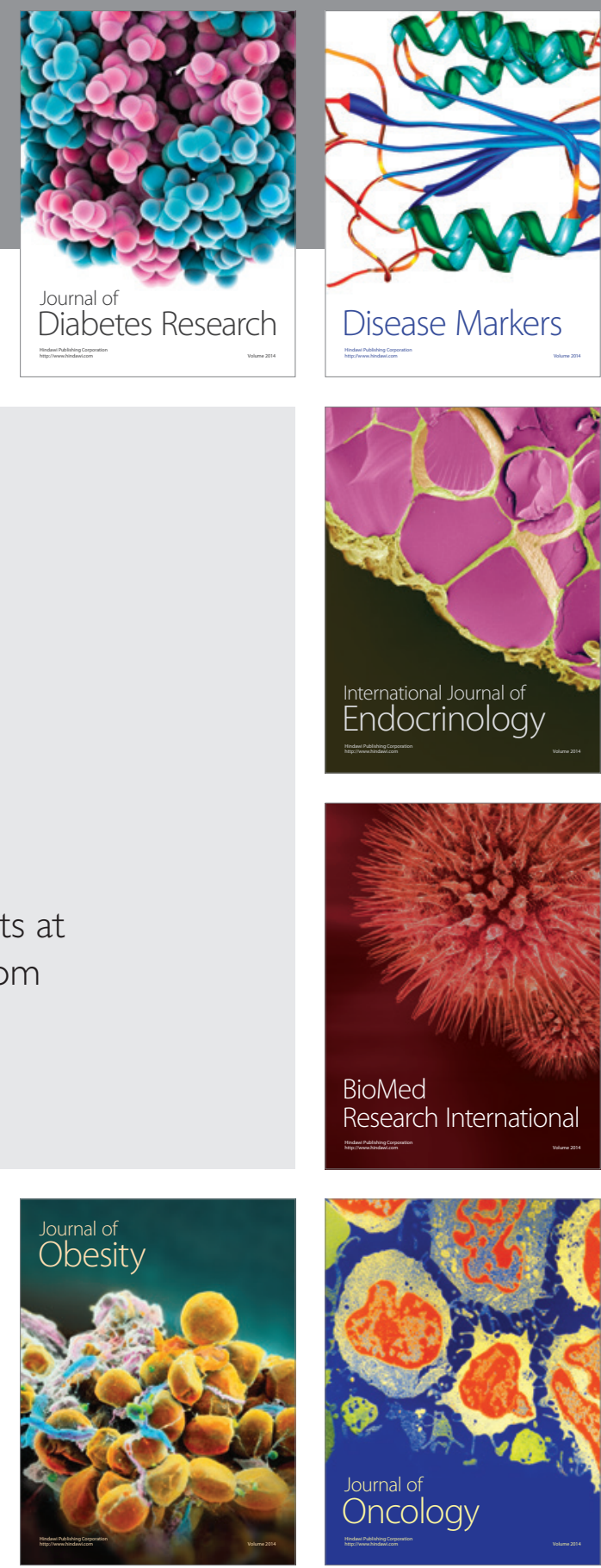

Disease Markers
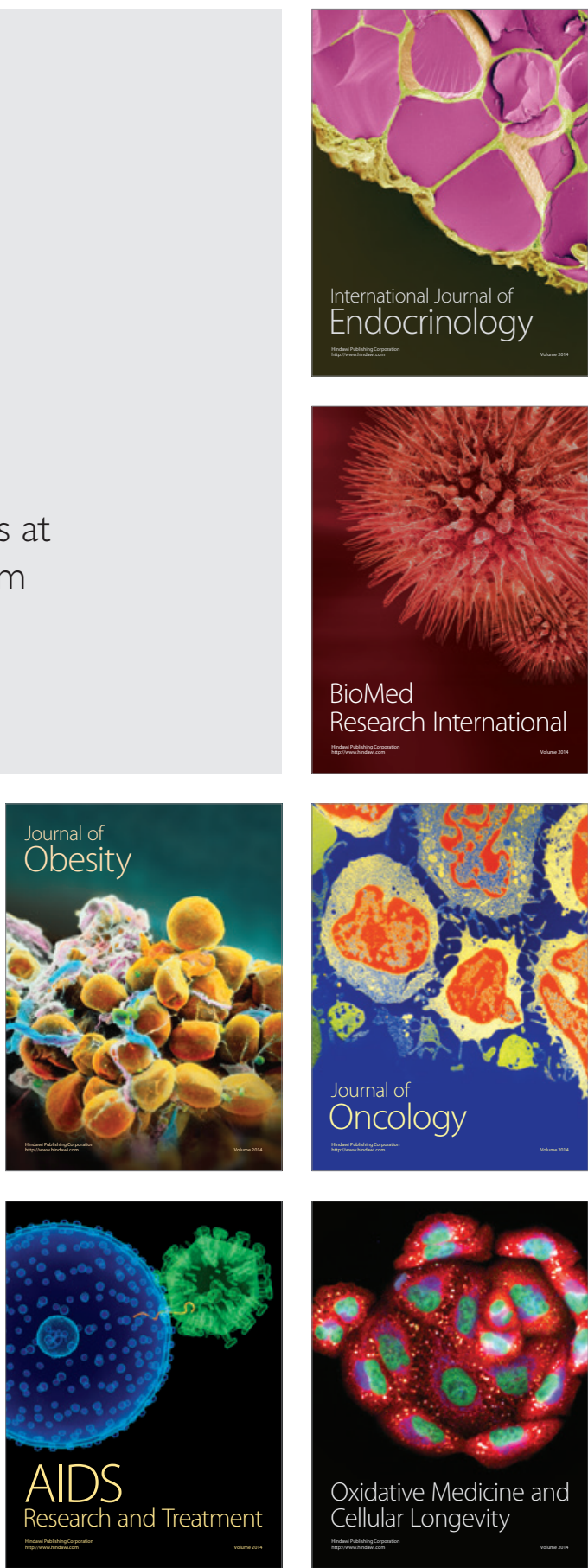